\title{
An observation of the banded structure of the Antarctic Coastal Current at the prime meridian
}

\author{
Ismael Núñez-Riboni' ${ }^{1}$ \& Eberhard Fahrbach ${ }^{2}$ \\ 1 Max Planck Institute for Meteorology, Bussestraße 53, DE-20146 Hamburg, Germany \\ 2 Alfred Wegener Institute for Polar and Marine Research, Bussestraße 24, DE-27570 Bremerhaven, Germany
}

\section{Keywords}

Antarctic Coastal Current; Antarctic Slope Front; countercurrent; current bands; sea ice; Southern Ocean.

\section{Correspondence}

Núñez-Riboni, Max Planck Institute for Meteorology, Bussestraße 53, DE-20146 Hamburg, Germany. E-mail:

ismael.nunez-riboni@zmaw.de

doi:10.1111/j.1751-8369.2010.00166.x

\begin{abstract}
Observations of three bands of westward flow and two countercurrents, spanning roughly $50 \mathrm{~km}$ from the ice-shelf edge in front of the Fimbul Ice Shelf (prime meridian) in Antarctica, are presented. A comparison with a numerical model and the proximity of two of these current cores to the ice shelf suggest that they split from the Antarctic Coastal Current because of the influence of sea ice on the surface drag. A comparison with previous studies suggests that the other core is the current associated with the Antarctic Slope Front. Because the Fimbul ice shelf overhangs the continental shelf, the Antarctic Coastal Current displaces offshore, getting close to the Antarctic Slope Front. The obtained structure is derived from conductivity-temperature-depth geostrophic velocities from February 2005, referenced with detided acoustic Doppler current profiler velocities.
\end{abstract}

In the Atlantic sector of the Southern Ocean, the Antarctic Slope Front (ASF; Jacobs 1986) and the Antarctic Coastal Current (ACoC; Deacon 1937) flow westwards along the Antarctic coast as a part of the southern branch of the Weddell Gyre. The ACoC in particlular is a key current for the advection of nutrients and krill (Heywood et al. 2004), and acts as a "dynamic barrier", keeping the warm deep water (WDW) of the Weddell Sea away from the ice shelf cavity of the Antarctic continent (Smedsrud et al. 2006). Most importantly, the southern branch of the Weddell Gyre is a major carrier of water masses to the formation areas of Antarctic deep water (AADW) and Antarctic bottom water (AABW) in the south-western Weddell Sea (Heywood et al. 2004).

Previous studies have revealed a banded structure of the Antarctic coastal flow at three regions around Antarctica: Gill (1973) and Foster \& Carmack (1976) found that the current along the Antarctic continental slope splits into coastal and slope components near $27^{\circ} \mathrm{W}$. Heywood et al. (1998) found that at $17^{\circ} \mathrm{W}$ the current associated with the ASF is split into two cores (one of them merged with the ACoC). Near Kapp Norvegia $\left(12^{\circ} \mathrm{W}\right)$, Fahrbach, Rohardt et al. (1994) also observed two westward bands flowing over the continental slope. The splitting of the coastal flow observed by Gill (1973) and Foster \& Carmack (1976) has been attributed to the widening of the continental shelf and the retreat of the coastline away from the continental slope. Fahrbach, Rohardt et al. (1994) explained the cores they found as a consequence of a step-like shape of the continental slope. However, Heywood et al. (1998) did not observe such a structure, and were not able to explain the splitting of the ASF.

In contrast to a one-banded flow, a multibanded flow generates areas of stronger and weaker horizontal shear, which impact transport (particularly of salt and heat), mixing and dynamics. Therefore, precise determination of the banded structure of the Antarctic coastal flow at several regions around Antarctica is important for identifying influences on the Antarctic ecosystem and on Antarctic water mass formation. This notion becomes obvious when considering transport estimates, which are generally calculated from geostrophic velocities derived from conductivity-temperature-depth (CTD) measurements from ships and/or with moored instruments. Both methods overlook the banded structure of the Antarctic coastal flow if the measurements do not occur in sufficient spatial resolution (e.g., Thompson \& Heywood 2008). At the prime meridian, the horizontal structure of the Antarctic coastal flow has been, until now, fully unknown. The present study fills this gap, addressing the question of the banded structure being permanent in time and space around Antarctica. 


\section{Data description and analysis}

The structure of the Antarctic coastal flow at the prime meridian was determined from measurements of CTD, and from ship-borne acoustic Doppler current profiler (ADCP) data from the RV Polarstern ANT-XXII/3 expedition on 17 and 18 February 2005. These data and the area of study are depicted in Fig. 1. The ADCP data are extracted into a $0.01^{\circ} \times 0.01^{\circ}$ horizontal grid (approximately $0.4 \mathrm{~km} \times 1 \mathrm{~km}$ in the study region).

To estimate the effect of internal waves generated by the baroclinic tides on the observed density field, the ratio between the variance of barotropic and baroclinic tides in the study region is calculated. Barotropic tides are calculated as the vertical mean of high-passed velocities (cut-off period of 7 days) of a current metre mooring positioned at the prime meridian and at $69.4^{\circ} \mathrm{S}$
(PANGAEA 2008), ca. $22 \mathrm{~km}$ away from the ice shelf (Fig. 1). The mean instrument depths are 247, 744 and 1925 m (in a water depth of 1975 m; Fig. 2a). Baroclinic tides are calculated from the deviation of the individual time series from the vertical mean. Only the period of time in which the CTD section was taken is considered. These measurements show that the vertical mean variance of the baroclinic tides is $6.2 \%$ of the variance of the barotropic tides. Therefore, the tides in the zone are essentially barotropic, and the effect of internal waves caused by baroclinic tides is minor.

The root mean square (RMS) velocity of the barotropic tide during the CTD section at the prime meridian of ANT-XXII/3 is $1.9 \mathrm{~cm} \mathrm{~s}^{-1}$, which represents $14.0 \%$ of the RMS velocity from the ADCP $\left(13.7 \mathrm{~cm} \mathrm{~s}^{-1}\right)$. These comparatively small tidal velocities are a consequence of low tidal amplitude in the study region (depths larger than
Fig. 1 (a) The grey rectangle near the coast in the eastern Weddell Sea indicates the study area in the Southern Ocean. (b) In a closer view of the area of study, arrows show the subsampled (for clarity) acoustic Doppler current profiler (ADCP) data of the Polarstern ANTXXII/3 expedition (21 January-6 April 2005). The seaward edge of the Fimbul ice shelf is indicated with a thick black line. Isobaths are given in 500-m steps, from 500 to $4000 \mathrm{~m}$ depth (Vanney \& Johnson 1985). Current velocities can be derived from the reference arrow in the lower left corner. Diamonds mark the positions of the conductivitytemperature-depth stations. The station inside the ring marks the position where the mooring used to detide the ADCP data was deployed.

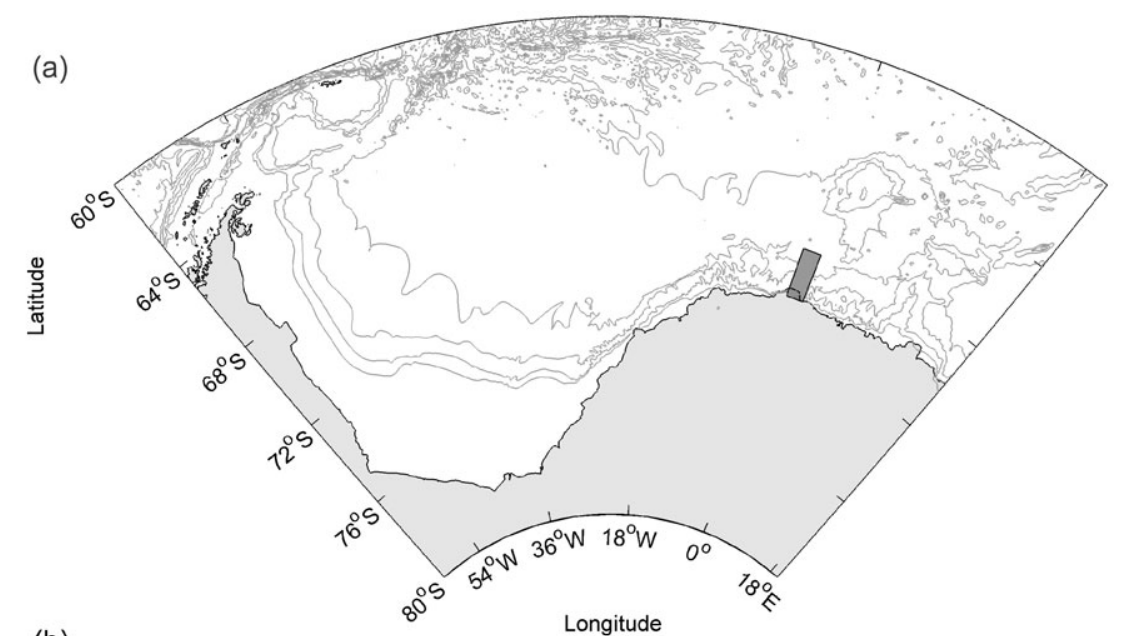

(b)

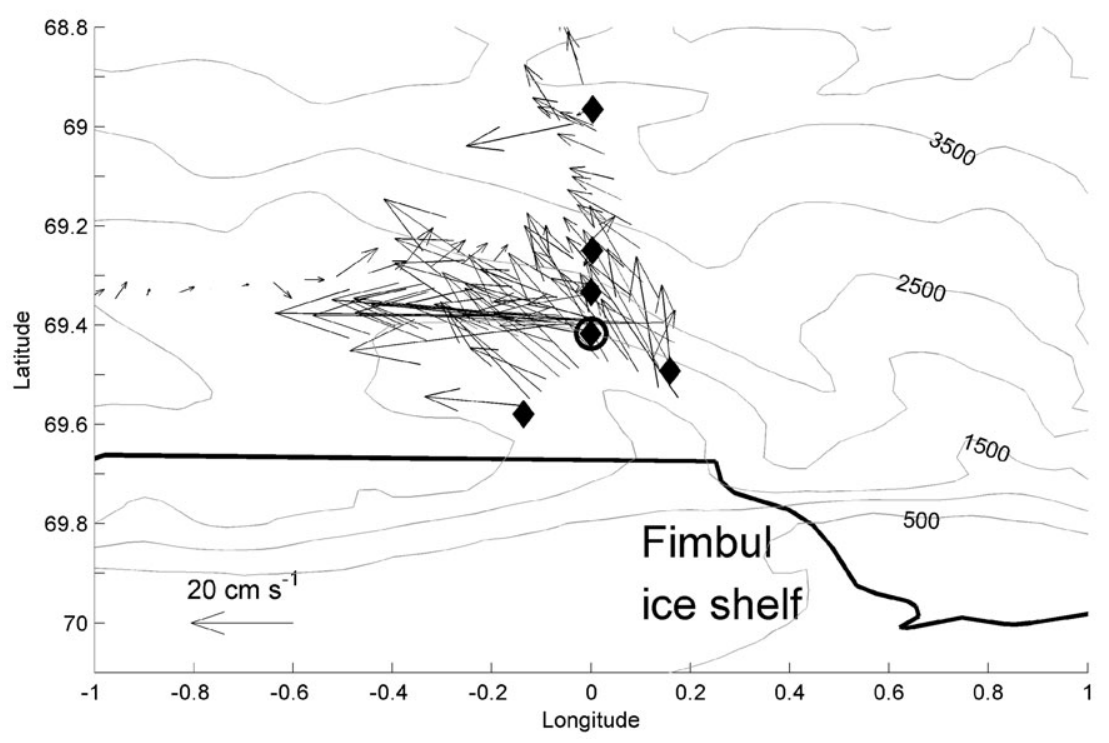


S M

(a)

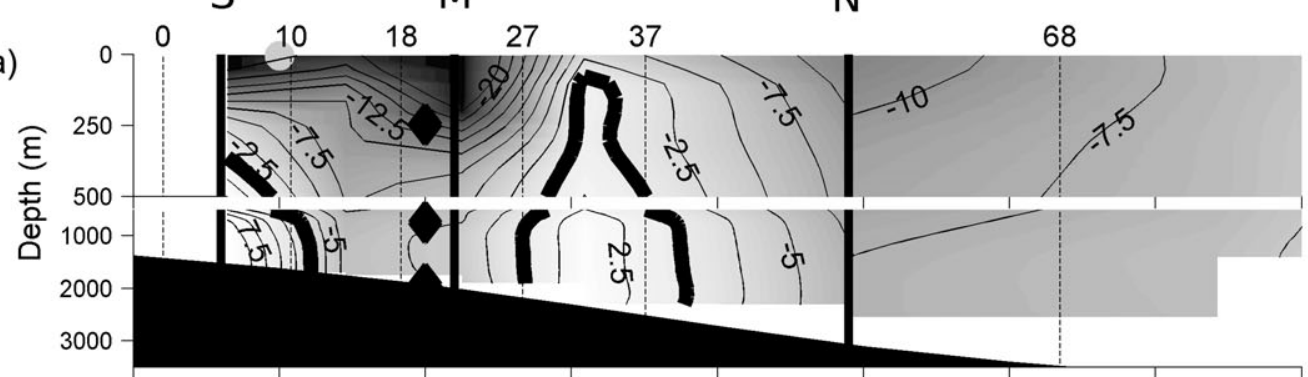

N

(b)

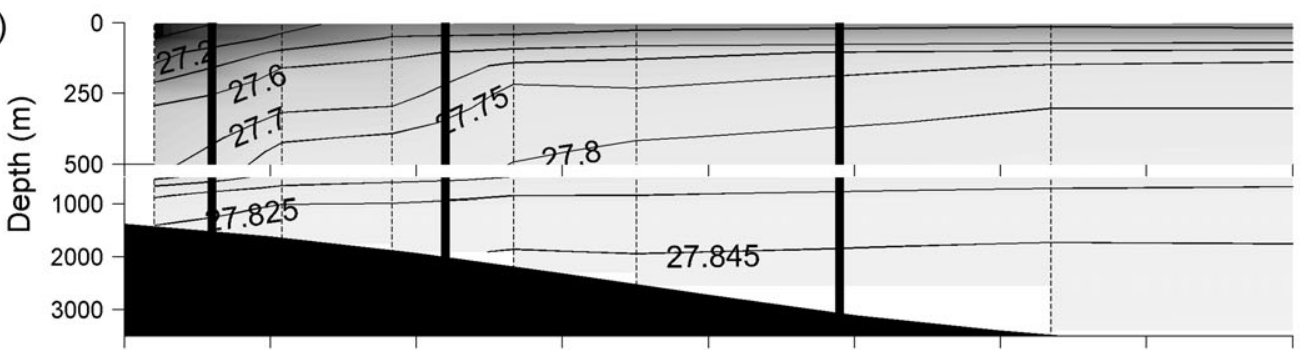

(c)

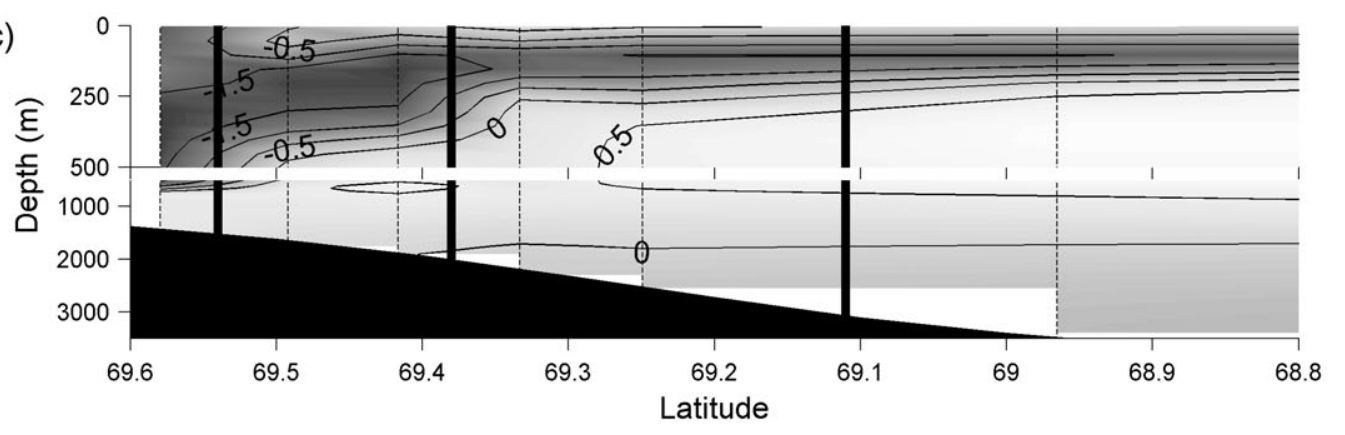

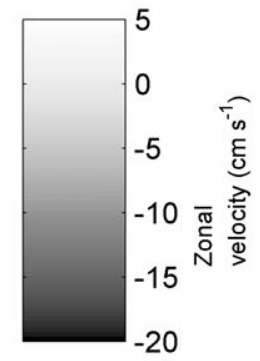

28

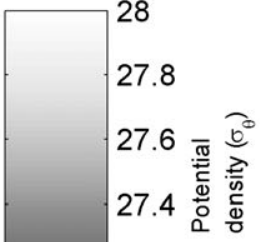

27.2

27

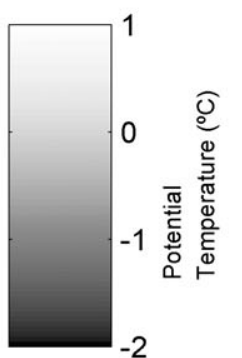

Fig. 2 (a) Geostrophic velocities derived from conductivity-temperature-depth (CTD) measurements referenced with detided acoustic Doppler current profiler (ADCP) velocities (positive eastwards). (b) Potential density anomaly $\sigma_{\theta}$ referred to the surface $\left(\mathrm{kg} \mathrm{m}^{-3}\right)$. (c) Potential temperature. The thin dashed lines indicate the position of the CTD stations. The numbers at the top indicate the meridional distance $(\mathrm{km})$ to the southernmost station. Bold vertical lines mark the current cores, which are identified with $\mathrm{S}$ for south, $\mathrm{M}$ for middle and $\mathrm{N}$ for north. The thick black contours in (a) indicate zero-velocity isolines, the diamonds show the positions of the moored instruments used to detide the ADCP velocities, and the grey disc at the surface (near $69.5^{\circ}$ ) shows the position where sea ice with $10 \%$ concentration was observed in the ASPeCt programme. The southern end of the displayed transect $\left(69.6^{\circ} \mathrm{S}\right)$ denotes the edge of the Fimbul ice shelf, as inferred from GPS positions from the RV Polarstern. Data farther north of the northernmost station has not been extrapolated, but has instead been interpolated with a station not shown in the figure. The depth axes are divided in two, from 0 to $500 \mathrm{~m}$ and from 500 to $3500 \mathrm{~m}$.

$1500 \mathrm{~m})$, together with the fact that the observations were taken during neap tide, as corroborated with the mooring time series. Such small tidal velocities are close to the accuracy of the ADCP (Garcia-Gorriz et al. 1997). Although this suggests that the detiding of ADCP data is of little effect in our results, the tides are removed from the ADCP velocities as follows.

The phase and velocity amplitude of the zonal velocity of each tidal harmonic are found with a least-squares minimization between mooring velocities and the sum of four harmonic functions, representing the principal tidal harmonics $M_{2}, S_{2}, K_{1}$ and $O_{1}$. An amplification factor for each tide harmonic is calculated as the amplitude change from the digitized co-tidal charts of Robertson et al. 1998 (their plate 1) between the mooring position and each ADCP data point. The phase shift for each tidal harmonic is calculated similarly. Tidal velocities of each harmonic are extrapolated from the mooring time series to each ADCP data point using the amplification factor and phase shift. Finally, the sum of the extrapolated four harmonics, $M_{2}, S_{2}, K_{1}$ and $O_{1}$, at each ADCP data point is subtracted from the ADCP zonal velocity.

This method is preferred to the direct subtraction of modelled tidal velocities (i.e., without using the mooring velocities) because it reproduces the mooring tide velocities with minimum RMS differences. Robertson et al.'s 
(1998) model is preferred above the high-latitude tidal models of the Earth and Space Research Institute and Oregon State University, TPXO7.1 (Egbert \& Erofeeva 2002) and CATS2008 (CATS 2008; Padman, pers. comm.) because RMS differences between model velocities extrapolated to the position of a second mooring $\left(69.0^{\circ} \mathrm{S}\right.$, $0^{\circ} \mathrm{E}$ ) and the observed tidal velocities are the smallest in the Robertson et al. (1998) model. The model results confirm that the observations were taken during neap tide.

Geostrophic velocities from CTD data are calculated relative to a reference level of $3500 \mathrm{~m}$ depth. Because the two southernmost stations are not exactly at the prime meridian (but approximately $8 \mathrm{~km}$ east and west of it; Fig. 1), the geostrophic velocities are projected into the zonal direction using the azimuth between CTD stations. For each pair of CTD stations, the projected profiles of geostrophic velocity are shifted until the mean geostrophic velocity between $50 \mathrm{~m}$ and the maximum depth of the ADCP (ca. $250 \mathrm{~m}$ ) matched the mean zonal detided ADCP velocity between the stations (for the same depth range). Only ADCP data deeper than $50 \mathrm{~m}$ is considered to avoid the influence of the ship and the Ekman layer, which is thinner than $40 \mathrm{~m}$, as calculated following Willebrand (1989).

The bathymetry used is the one-minute grid of the General Bathymetric Chart of the Oceans (Vanney $\&$ Johnson 1985). Sea-ice observations were taken on-board the Polarstern and are now available from the data archive Antarctic Sea Ice Processes and Climate (ASPeCt 2008).

\section{Results}

The absolute zonal geostrophic velocities (Fig. 2a) show that the coastal flow at the prime meridian is approximately $50 \mathrm{~km}$ wide at the surface, and is split in three westward current bands: at $69.54^{\circ} \mathrm{S}$ (labelled S, for south), $69.38^{\circ} \mathrm{S}$ (labelled $\mathrm{M}$, for middle) and $69.11^{\circ} \mathrm{S}$ (labelled $\mathrm{N}$, for north). The cores are also visible in the density field (Fig. 2b), with isopycnals $\sigma_{\theta}$ inclined downwards towards the coast. An uncertainty for the zonal geostrophic velocity of $S$ could arise because of the unknown velocity component parallel with the line connecting the two southernmost CTD stations (Fig. 1). However, because the velocity field is prescribed at the surface with ADCP data, the uncertainty is related only to the shear of $S$.

Centred at the continental slope $\left(69.29^{\circ} \mathrm{S}\right)$ and at the ice-shelf edge $\left(69.55^{\circ} \mathrm{S}\right)$, there are two countercurrents at the sea bed, with eastward velocities of ca. 5 and $10 \mathrm{~cm} \mathrm{~s}^{-1}$, respectively (Fig. 2a). The transport of the first countercurrent is ca. 1.6 Sv. The second countercurrent seems to be partially under the ice shelf, and therefore its transport cannot be estimated. A patch of warm water near $69.5^{\circ} \mathrm{S}$ at a depth of $100 \mathrm{~m}$ suggests downwelling (Fig. 2c).

To estimate the effect on the transport calculations when the banded structure of the current is not considered (e.g., Thompson \& Heywood 2008), the geostrophic transport has been calculated by using all CTD stations and by removing the CTD station at $69.5^{\circ} \mathrm{S}$, which merged the two bands near the ice shelf into one. The transport is underestimated by $12 \%$ if this CTD station is removed, suggesting that the omission of the banded structure yields a significant transport inaccuracy.

\section{Discussion}

Heywood et al. (1998) mention the splitting of the current associated with the ASF into two cores. They state that the southern core is merged with the ACoC in their study region, and match this splitting with that of the "eastern boundary currents" of the Weddell Gyre observed by Fahrbach, Rohardt et al. (1994). Both studies observe a current core near the ice front and a slower core offshore (Heywood et al. 1998: fig. 5b; Fahrbach, Rohardt et al. 1994: fig. 6). In the case of Heywood et al. (1998), the southern core has a speed of $30 \mathrm{~cm} \mathrm{~s}^{-1}$ and the northern core has a speed of $20 \mathrm{~cm} \mathrm{~s}^{-1}$, and they are separated from each other by ca. $50 \mathrm{~km}$. These observations coincide roughly with cores $\mathrm{M}$ (ca. $30 \mathrm{~cm} \mathrm{~s}^{-1}$ ) and $\mathrm{N}$ (ca. $12 \mathrm{~cm} \mathrm{~s}^{-1}$ ) in this paper, which are separated by ca. $30 \mathrm{~km}$ from each other. In both previous studies, the southern core has been observed to flow along the ice-shelf front, in regions of strong density gradients in which the isopycnals slope downward towards the coast. South of $69.3^{\circ} \mathrm{S}$, the same density structure is observed at the prime meridian (Fig. 2b; also observed by Fahrbach, Rohardt et al. [1994], and modelled by Smedsrud et al. [2006]), where bands S and $\mathrm{M}$ are located. The northern band reported in both previous studies flows over the deeper part of the continental slope (at a depth of ca. $3000 \mathrm{~m}$ ), which is also the position of $\mathrm{N}$ (ca. $3100 \mathrm{~m}$; Fig. 2a). These correspondences suggest that $\mathrm{S}$ and $\mathrm{M}$ are related to the near-shore core observed by Heywood et al. (1998) and Fahrbach, Rohardt et al. (1994), i.e., the ACoC and N to their offshore core (the current associated with the ASF). Whereas the ACoC normally flows over the continental shelf of Antarctica (Heywood et al. 2004), the current is generated mainly by the wind, which piles up water against the ice shelf front as a result of Ekman transport. Therefore, the Fimbul ice shelf overhanging the continental shelf (Fig. 1) displaces the current offshore, and brings it closer to the ASF. 
(a)

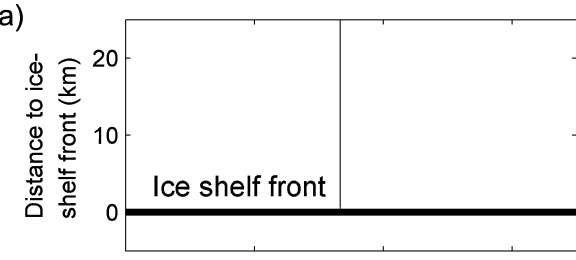

(b)

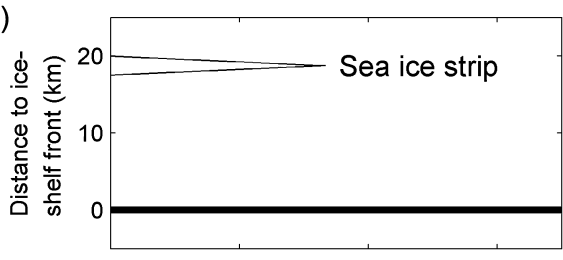

(c)

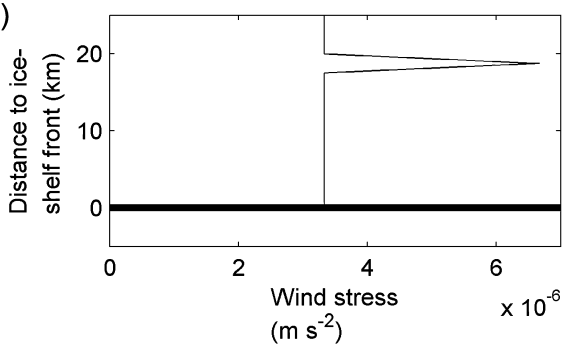

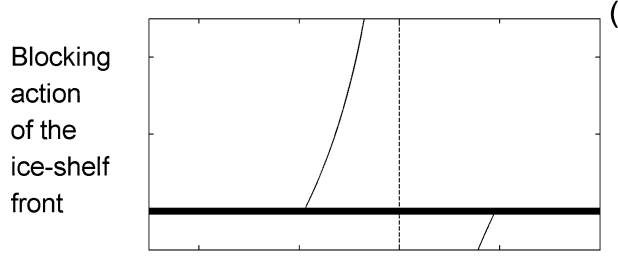

(d)

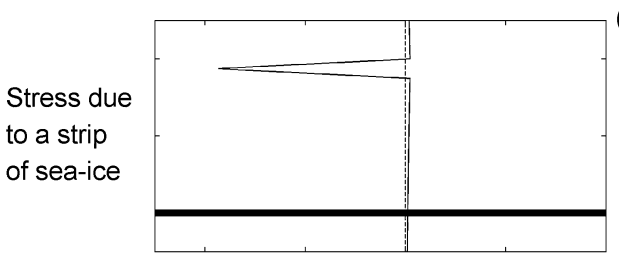

(e)

(f)

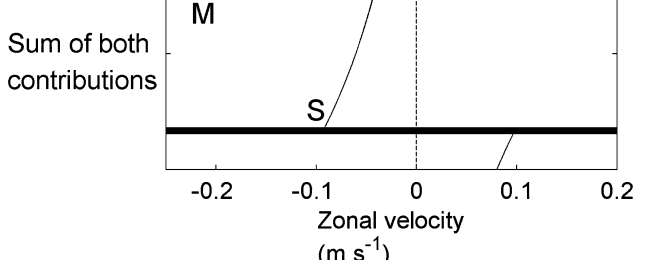

Fig. 3 (a-c) Wind stress profiles. (d-f) The resulting zonal velocity fields derived from the theory of Fennel \& Johannessen (1998). In (a) and (d) the problem of the fixed ice shelf is shown. Using eqn. 32 of Fennel \& Johannessen (1998), (a) shows a constant wind stress over the open ocean, whereas (d) shows the non-oscillatory part of the solution: a geostrophic along-edge jet in downwind direction in front of the ice shelf and a countercurrent underneath. Stress generated by a strip of zonally moving sea ice is shown in (b), and (e) shows the corresponding downwind jet. (c) The sum of both wind stresses and (f) resulting velocity fields are also represented. The ice-shelf front is represented by the horizontal thick lines. The region in which $y<0$ is the Antarctic continent; the region in which $y>0$ is the ocean. The wind stress represents winds towards the west. Because in Fennel \& Johannessen (1998) the wind is assumed to force the ocean evenly across the mixed layer, the wind stress is scaled by the density and depth of the mixed layer (i.e., the stress is given by the squared friction velocity per unit depth; $\mathrm{m} \mathrm{s}^{-2}$ ). Negative current velocities $\left(\mathrm{m} \mathrm{s}^{-1}\right)$ are westwards. The north is upwards. In (f), the two resulting current bands, which would be related to those of Fig. 2, are marked with S (for south) and $\mathrm{M}$ (for middle). The parameters from the Fennel \& Johannessen (1998) analysis are subjectively chosen: the depth of the mixed layer is taken as $30 \mathrm{~m}$, the friction velocity is taken as $1 \mathrm{~cm} \mathrm{~s}^{-1}$ and the width of the ice floes is taken as $500 \mathrm{~m}$. The baroclinic Rossby radius $R$ is taken as $5 \mathrm{~km}$, based on Houry et al. (1987). This solution corresponds to the eighth time step after starting the wind stress (the analysis of Fennel \& Johannessen [1998] is not stationary).

Whereas Heywood et al. (1998) found that the ASF splits into two cores, they did not observe any splitting of the ACoC. However, they could not explain the splitting of the ASF. The step-like topography related to a plateau in the continental slope at intermediate depth that Fahrbach, Rohardt et al. (1994) observed, and which they proposed to generate the cores, was not observed by Heywood et al. (1998). In the present study, there is also no evidence of plateau-like structures to yield the current bands. Zonation resulting from the beta plane (e.g., Sokolov \& Rintoul 2007) is also improbable: the Rhines scale (Rhines 1975), characterizing the conditions under which bands are formed in the study region, is ca. $700 \mathrm{~km}$ (eqn. 5 of Read et al. [2007], using a typical velocity of $20 \mathrm{~cm} \mathrm{~s}^{-1}$ at $\left.69^{\circ} \mathrm{S}\right)$. This value is considerable larger than the observed distance between the bands.
On the other hand, splitting of the ACoC (and not of the ASF) by sea ice is a more likely cause for the observed current bands. To provide evidence that a strip of sea ice in front of the Antarctic ice shelf can divide the ACoC into bands, solutions of hydrostatic Boussinesq equations for a flat-bottomed, f-plane ocean near an ice shelf (Fennel 8 Johannessen 1998) were used. The contribution of the pressure gradient resulting from water piled against the ice-shelf front by Ekman transport (Fig. 3a, d) is obtained from the first term of eqn. 32 of Fennel $\&$ Johannessen (1998): the non-oscillatory part of the solution to the problem of the fixed ice shelf (Clarke 1978). The contribution to the velocity field of a strip of sea ice (Fig. 3b, e) is obtained from the solution of eqn. 54 of Fennel $\delta$ Johannessen (1998), by taking by taking their constants $C_{0}$ and $A_{0}$ as zero (these measures neglect the wind stress 
over the entire area apart from a band representing the sea-ice strip). The sum of both contributions (Fig. 3c, f) is remarkably similar to the observed banded structure of the ACoC (Fig. 2a). In this solution to the equations of motion of Fennel \& Johannessen (1998), the stress over the sea ice is larger than over the open ocean, which occurs when ridged sea ice is present: the ice behaves like a sail, increasing the drag (Luepkes \& Birnbaum 2005). In agreement with this notion, the on-board ice observations during ANT-XXII/3 (ASPeCt 2008) show a strip of first-year sea ice near $69.5^{\circ} \mathrm{S}$ (Fig. 2a).

Further similarities between the observation and Fennel \& Johannessen's (1998) theory reinforce this idea: the countercurrent below the ice shelf predicted by Fennel $\&$ Johannessen (1998) and Clarke (1978) (Fig. 3d) would relate to an eastward velocity of $10 \mathrm{~cm} \mathrm{~s}^{-1}$ close to the ocean bottom and the ice shelf in Fig. 2a. The solution of Fennel \& Johannessen's (1998) eqn. 54, although with $C_{0} \neq 0$, predicts downwelling at the position of the nearcoast core and a countercurrent seaward of the offshore core (Fennel \& Johannessen 1998: fig. 5). Accordingly, S lies near a patch of warm surface water downwelled to $100 \mathrm{~m}$ near $69.50^{\circ} \mathrm{S}$ (water with temperatures equal or higher than $-1^{\circ} \mathrm{C}$; Fig. 2c), and there is a countercurrent immediately north of $\mathrm{M}$ (near $69.3^{\circ} \mathrm{S}$, Fig. 2a).

Although two countercurrents along the Antarctic ice shelf have not yet been observed simultaneously, this is probably because of their different dynamics: the first countercurrent is generated by the blocking action of the ice-shelf front (Clarke 1978; Fennel \& Johannessen 1998), and hence it is a permanent feature, but is difficult to observe because it is below the ice shelf. The second countercurrent is linked to the sea ice, and hence it appears seaward of the ice-shelf front, but as a semipermanent feature changing position and intensity. In previous studies there is evidence of either one or the other countercurrent: a countercurrent below the Fimbul ice shelf has been modelled by Smedsrud et al. (2006), west of $2^{\circ} \mathrm{W}$ at a depth of ca. $500 \mathrm{~m}$. Fahrbach, Peterson et al. (1994) found a north-eastward undercurrent $\left(4 \mathrm{~cm} \mathrm{~s}^{-1}\right.$; their fig. 4) counter to the prevailing coastal flow at a similar depth of the countercurrent at the continental slope in the present study (between 1000 and 1500 m). Similarly, Heywood et al. (1998) report an undercurrent near $17^{\circ} \mathrm{W}$, trapped close to the continental slope and carrying $0.16 \mathrm{~Sv}$ along the isobaths between 700 and $1100 \mathrm{~m}$. The transport discrepancy between Heywood et al. (1998) and the present study (1.6 Sv) could be related to different sea-ice conditions, wind and hydrography forcings between the two studies.

These similarities with Fennel \& Johannessen's (1998) theory suggest that the $\mathrm{ACoC}$ is generated as a single current band by Ekman transport piled against the ice- shelf front. The ACoC splits in two current bands because of the increased wind drag of sea ice compared with open water: a strip of sea ice flowing along the ice shelf (separated from it by a polynya) generates a band of high velocity. The intensity of this current band depends on the influence of the sea ice on the surface drag coefficient, i.e., on the roughness and concentration of the sea ice. The only disagreement between theory and observation is the position of the sea-ice strip: in the observation it lies between the two cores (Fig. 2a), rather near the slow core $\mathrm{S}$, whereas in the theory it lies over the fast core $\mathrm{M}$ (Fig. 3). Such discrepancies are usual when comparing observations and numerical models, and can be related to various factors: coarse spacing between CTD stations, human errors in the sea-ice observations, or greater complexity in the actual influence of the sea ice on the dynamics of currents than in the simplified scheme presented by Fennel \& Johannessen (1998).

A scenario in agreement with the notion of Heywood et al. (1998) is also possible: core M could be part of the current associated with the ASF, whereas core S alone would constitute the ACoC (i.e., the ASF would split into cores $\mathrm{M}$ and $\mathrm{N}$ ). Then again, as there is no obvious reason for the splitting of the ASF, splitting of the ACoC as a result of sea ice seems to be the most probable scenario.

Finally, it is worth discussing how representative of the mean conditions of the ACoC is the presented geostrophic field: the composite mean velocity of the barotropic component for mid-February (when the CTD section of ANT$\mathrm{XXII} / 3$ was taken) is calculated from the mooring at $69.4^{\circ} \mathrm{S}$ to be $6 \pm 4 \mathrm{~cm} \mathrm{~s}^{-1}$ (filtered to 7 days to eliminate tides). The vertical mean of the absolute geostrophic velocities of ANT-XXII/3 for the position of the mooring is $8.9 \mathrm{~cm} \mathrm{~s}^{-1}$, lying inside the range of the mid-February composite velocity. This suggests that the CTD section of ANT-XXII/3 represents a typical flow of the ACoC in summer. Furthermore, because the sea ice in the study region is normally separated from the ice shelf by a polynya, the banded structures of sea ice and ACOC observed in the present study are expected to be common.

In previous studies in this region (Fahrbach et al. 2004; Klatt et al. 2005), the banded structure of the ACoC has not been observed because of the coarse spacing between CTD stations or the failure to find a layer of known motion. In order to reveal this structure, it is recommended for future studies that the spacing between CTD stations be equal to or smaller than the smallest distance between the stations of the present study (10 km; Fig. 2a).

\section{Summary and conclusions}

In the present study, the structure of the Antarctic coastal flow at the prime meridian is derived from hydrographic 
data from CTD and detided ADCP velocities. Three bands of westward flow, spanning approximately $50 \mathrm{~km}$ off the ice-shelf edge, are revealed. Their proximity to the iceshelf front and the similarity of their structure with Fennel \& Johannessen's (1998) model results suggest that the two near-shore bands are split from the AcoC, as a result of the influence of the sea-ice concentration on the surface drag. A countercurrent on the continental slope, also observed in previous studies (Fahrbach, Peterson et al. 1994; Heywood et al. 1998), and downwelling agree with Fennel \& Johannessen's (1998) scheme, supporting the notion of the influence of sea ice on the dynamics of the ACoC.

The offshore band could be related to the ASF because its position relative to the bottom slope coincides with the position of this front, as observed in previous studies (Fahrbach, Rohardt et al. 1994; Heywood et al. 1998). The velocities of the observed bands and their positions relative to the water mass properties are also those of the ACoC and the current associated with the ASF, as reported by Fahrbach, Rohardt et al. (1994) and Heywood et al. (1998). The proximity between the ACoC and the ASF in the present study is related to the Fimbul ice shelf overhanging the continental shelf, which displaces the ACoC seaward.

Comparison of the transport estimates from a CTD section including all of the bands, with a section in which one band was ignored, shows that neglecting the bands of the $\mathrm{ACoC}$ results in an underestimation of the transport by $12 \%$.

\section{Acknowledgements}

The kind cooperation of Gerd Rohardt, Boris Cisewski, Anna Akimova, Carmen Böning, Nikolay Koldunov and Svetlana Erofeeva is highly appreciated. Discussions with Laurence Padman and Wolfgang Fennel are especially acknowledged. The authors are also grateful to the German Research Foundation for a research grant (Geschäftszeichen: FA 436/2-3), to the officers, crew and members of the CTD group of the Polarstern ANT-XXII/3 expedition, and to four anonymous reviewers (two of whom examined an earlier version of this paper that was rejected) for their helpful suggestions. INR was at the Alfred Wegener Institute for Polar and Marine Research at the time the research reported here was carried out.

\section{References}

ASPeCt 2008. Individual ship-based sea-ice observations. Antarctic Sea Ice Processes and Climate. Accessed on the internet at http://www.aspect.aq/data.html on 7 September 2008.

CATS 2008. CATS2008a_opt: Circum-Antarctic Tidal Simulation, Inverse Model version 2008a. Accessed on the internet at http://www.esr.org/antarctic/barotropic.html in January 2009.

Clarke A.J. 1978. On wind-driven quasi-geostrophic water movements near fast-ice edges. Deep Sea Research 25, 41-51.

Deacon G.E.R. 1937. The hydrology of the Southern Ocean. Discovery Reports 15. London: Discovery Committee Colonial Office.

Egbert G.D. \& Erofeeva S.Y. 2002. Efficient inverse modeling of barotropic ocean tides. Journal of Atmospheric and Oceanic Technology 19, 183-204.

Fahrbach E., Hoppema M., Rohardt G., Schroder M. \& Wisotzki A. 2004. Decadal-scale variations of water mass properties in the deep Weddell Sea. Ocean Dynamics 54, 77-91.

Fahrbach E., Peterson R.G., Rohardt G., Schlosser P. \& Bayer R. 1994. Suppression of bottom water formation in the southeastern Weddell Sea. Deep-Sea Research Part I 41, 389-411.

Fahrbach E., Rohardt G., Schroeder M. \& Strass V. 1994. Transport and structure of the Weddell Gyre. Annales Geophysicae 12, 840-855.

Fennel W. \& Johannessen O.J. 1998. Wind forced responses near ice edges revisited. Journal of Marine Systems 14, 57-79.

Foster T.D. \& Carmack E.C. 1976. Frontal zone mixing and Antarctic Bottom Water formation in the southern Weddell Sea. Deep-Sea Research 23, 301-317.

Garcia-Gorriz E., Font J. \& Candela J. 1997. Data quality control for vessel mounted acoustic Doppler current profiler. Application for the western mediterranean sea. Scientia Marina 61, 417-430.

Gill A.E. 1973. Circulation and bottom water production in the Weddell Sea. Deep-Sea Research 20, 111-140.

Heywood K.J., Locarnini R.A., Frew R.D., Dennis P.D. \& King B.A. 1998. Transport and water masses of the Antarctic Slope Front system in the eastern Weddell Sea. In S.S. Jacobs \& R.F. Weiss (eds.): Ocean, ice, and atmosphere: interactions at the Antarctic Continental Margin. Pp. 203-214. Washington, D.C.: American Geophysical Union.

Heywood K.J., Naveira-Garabato A.C., Stevens D.P. \& Muench R.D. 2004. On the fate of the Antarctic Slope Front and the origin of the Weddell Front. Journal of Geophysical Research-Oceans 109, C06021, doi: 10.1029/ 2003JC002053.

Houry S., Dombrowsky E., DeMey P. \& Minster J. F. 1987. Brunt-Väisälä frequency and Rossby radii in the South Atlantic. Journal of Physical Oceanography 17, 1619-1626.

Jacobs S.S. 1986. The Antarctic Slope Front. Antarctic Journal of the United States 21, 123-124.

Klatt O., Fahrbach E., Hoppema M. \& Rohardt G. 2005. The transport of the Weddell Gyre across the Prime Meridian. Deep-Sea Research Part II 52, 513-528. 
Luepkes C. \& Birnbaum G. 2005. Surface drag in the Arctic marginal sea-ice zone: a comparison of different parameterisation concepts. Boundary-Layer Meteorology 117, 179-211.

PANGAEA 2008. Publishing Network for Geoscientific \& Environmental Data. DOIs of the moorings data: 10.1594/PANGAEA.510179-10.1594/PANGAEA.510182. Accessed on the internet at http://www.pangaea.de in August 2007.

Read P.L., Yamazaki Y.H., Lewis S.R., Williams P.D., Wordsworth R., Miki-Yamazaki K., Sommeria J. \& Didelle H. 2007. Dynamics of convectively driven banded jets in the laboratory. Journal of the Atmospheric Sciences 64, 4031-4052.

Rhines P.B. 1975. Waves and turbulence on a beta-plane. Journal of Fluid Mechanics 69, 417-443.

Robertson R., Padman L. \& Egbert G.D. 1998. Tides in the Weddell Sea. In S.S. Jacobs \& R.F. Weiss (eds.): Ocean, ice, and atmosphere: interactions at the Antarctic Continental Margin.
Pp. 341-369. Washington, D.C.: American Geophysical Union.

Smedsrud L.H., Jenkins A., Holland D.M. \& Nost O.A. 2006. Modeling ocean processes below Fimbulisen, Antarctica. Journal of Geophysical Research-Oceans 111, C01007, doi: 10.1029/2005JC002915.

Sokolov S. \& Rintoul S.R. 2007. Multiple jets of the Antarctic Circumpolar Current south of Australia. Journal of Physical Oceanography 37, 1394-1412.

Thompson A.F. \& Heywood K.J. 2008. Frontal structure and transport in the northwestern Weddell Sea. Deep-Sea Research Part I 55, 1229-1251.

Vanney J.R. \& Johnson G.L. 1985. GEBCO bathymetric sheet 5.18 (circum-Antarctic). In S.S. Jacobs (ed.): Oceanology of the Antarctic Continental Shelf. Pp. 1-3. Washington, D.C.: American Geophysical Union.

Willebrand J. 1989. General circulation dynamics. In J. Sündermann (ed.): Oceanography. Pp. 123-150. Berlin: Springer. 